\title{
Gastroesophageal reflux symptoms in infants in a rural population: longitudinal data over the first six months
}

\author{
Robert S Van Howe ${ }^{1 *}$, Michelle R Storms ${ }^{2}$
}

\begin{abstract}
Background: Increasing numbers of infants are receiving prescription medications for symptoms associated with gastroesophageal reflux. Our aim was to prospectively measure reported gastroesophageal reflux symptoms in healthy term infants for the first six months of life.

Methods: In a prospective cohort study in the rural Upper Peninsula of Michigan, 128 consecutive maternal-infant pairs were followed for six months and administered the Infant Gastroesophageal Reflux Questionnaire Revised (IGERQ-R) at the one-month, two-month, four-month, and six-month well-child visits.

Results: The I-GERQ-R scores decreased with age. Average scores were 11.74 (SE = 5.97) at one-month, 9.97(4.92) at two-months, 8.44(4.39) at four-months, and 6.97(4.05) at six months. Symptoms associated with colic were greatest at one month of age.

Conclusion: Symptoms of gastroesophageal reflux as measured by the I-GERQ-R decrease with age in the first six months of life in otherwise healthy infants; however the I-GERQ-R may have difficulty differentiating gastroesophageal reflux disease from colic in those under 3 months of age.
\end{abstract}

\section{Background}

Gastroesophageal reflux (GER) can be a normal physiological process that occurs in healthy infants, children, and adults. GER occurs when gastric contents move into the esophagus as the result of transient relaxations of the lower esophageal sphincter (LES), an abrupt decrease in LES pressure to the level of intragastric pressure unrelated to swallowing, or when the LES tone does not compensate for changes in abdominal pressure [1]. The definition of gastroesophageal reflux disease (GERD), especially in infants, is nebulous. Recently, an expert panel opined that GERD occurred when the reflux of gastric contents is the cause of "troublesome symptoms" and/or complications. "Troublesome" was defined as having "an adverse effect on the well-being" of the patient. The panel did not endorse any objective measures for diagnosing GERD[2].

\footnotetext{
* Correspondence: vanhowe@miuplink.net

'Department of Pediatrics and Human Development, Michigan State University College of Human Medicine, Marquette, Michigan, USA
}

Another expert panel concluded that there was no evidence to support an empiric trial of acid suppression in infants with symptoms associated with GER[3]. Despite this, many physicians, seeing that parents are concerned or upset by their infant's continual spitting up, are now prescribing both histamine type 2 blocking agents and proton pump inhibitors[4].

The symptoms of GER are nonspecific, making it difficult to distinguish the fussiness, crying, and irritability normally seen in the first months of life from colic, food protein intolerance, or GERD [5-9].

To determine the degree of GER-associated symptoms in a healthy population of infants, we undertook the first prospective cohort study of nonselected infants from birth to six-months of age using the Infant Gastroesophageal Reflux Questionnaire Revised (I-GERQ-R) [10].

\section{Methods}

A consecutive sample of mother-infant pairs who delivered at Marquette General Hospital, a rural referral hospital, was obtained. Exclusion criteria included follow-up 
with physicians not participating in the study (primarily outside of Marquette, Michigan), gestational age of less than 36 weeks, twins, and admission to the neonatal intensive care unit.

The I-GERQ-R, a validated survey tool, was used to determine the frequency and severity of GER symptoms [10]. The survey was completed by the mother at the one-month, two-month, four-month, and six-month well child visits with the infant care provider. Each question of the survey was evaluated for changes with age.

Comparisons of I-GERQ-R and regurgitation frequency were made. The four items of the I-GERQ-R that addressed symptoms associated with colic (crying, back arching) [6,7] were compared by age to the eight items associated primarily with regurgitation.

Evaluations of changes in scores from visit to visit were made using a t-test. I-GERQ-R scores in those babies currently primarily breastfed were compared to those not primarily breastfed for each postnatal visit. Calculations were performed with SAS version 8.2 (SAS Institute, Cary, North Carolina).

Informed consent was obtained from the mother before entry into the study. This study protocol was approved by the Marquette General Hospital Institutional Review Board.

\section{Results}

A total of 128 mother-infant pairs of the 131 who met the inclusion criteria were enrolled in the study from January 23, 2006 to October 3, 2006. The mothers in our study averaged 27.6 (standard deviation $(\mathrm{SD})=5.5$ ) years old with $1.98(\mathrm{SD}=1.01)$ children and $2.1(\mathrm{SD}=$ 0.59 ) adults in the home. The babies averaged 39.6 (SD = 1.1) weeks gestational age, birthweight of 3536 (SD = 460) grams, length of $49.9(\mathrm{SD}=2.5)$ centimeters, and head circumference of 34.4 ( $\mathrm{SD}=1.7)$ centimeters. A review of 2098 infants born at our facility from 1999 through 2001 found that $95.19 \%$ were Caucasian, 2.43\% Native American, $1.00 \%$ mixed race, $0.86 \%$ African American, 0.33\% Hispanic, and 0.19\% Asian American [11]. No shift in the racial/ethnic characteristics of this population has occurred in the intervening years.

The results of the I-GERQ-R surveys by age of visit are given in Table 1 and Figure 1. The leftward shift of the lines with age on Figure 1 indicates a leftward shift of the distribution of I-GERQ-R scores with age consistent with falling scores. The differences in individual patients between I-GERQ-R scores between the onemonth and two-month visits was -1.52 (standard error $(\mathrm{SE})=0.49, \mathrm{p}<.05)$, the one-month and four-month visits was $-3.63(\mathrm{SE}=0.56, \mathrm{p}<.0001)$, the one-month and six-month visits was $-5.43(\mathrm{SE}=0.63, \mathrm{p}<.0001)$, the two-month and four-month visits was -1.69 (SE $=$
$0.52, \mathrm{p}<.01)$, the two-month and six-month visits was $-3.16(\mathrm{SE}=0.54, \mathrm{p}<.0001)$, and the four-month and six-month visits was $-1.29(\mathrm{SE}=0.46, \mathrm{p}<.01)$. Each visit resulted in a statistically significant decrease in the I-GERQ-R score from the previous visit. The results of the individual questions of the survey by each visit are shown in Table 2.

Considering a positive score as being an I-GERQ- $R$ score of 16 or greater, 24 of $94(25.5 \%, 95 \% \mathrm{CI}=16.7 \%$ $34.4 \%)$ of one-month-olds were positive. At two months this dropped to 12 of $96(12.5 \%, 95 \% \mathrm{CI}=5.9 \%-19.1 \%)$. At four months 8 of $100(8.0 \%, 95 \% \mathrm{CI}=3.7 \%-13.3 \%)$ were positive, and at six months 3 of $103(2.9 \%, 95 \% \mathrm{CI}$ $=0 \%-6.2 \%)$ were positive.

The regurgitation frequency remained fairly constant through four months of age (average regurgitations per day: one-month 2.31 (SD = 1.90), two-month 2.19 (SD $=1.89)$, four-month $2.30(\mathrm{SD}=1.87))$ then dropped at six months of age (average regurgitations per day 1.46 $(S D=1.53)$, while the I-GERQ-R showed a steady decline with age. When colic-associated scores and regurgitation scores by age were compared, the colicassociated symptoms dropped more quickly over the first two time periods. This is confirmed by a lower percentage of the total I-GERQ-R score contributed by colic-associated symptoms at two months and four months (one-month $35.2 \%$, two-month $32.4 \%$, fourmonth 29.4\%). The rise in the percentage at six months (32.4\%) resulted primarily from the drop in regurgitation seen between four and six months of age.

We found no correlation between maternal smoking and colic-associated symptom scores or I-GERQ-R scores. Likewise at each postnatal visit there was no difference in I-GERQ-R scores in those infants who were currently primarily breastfed and those who were not (one-month: difference $=0.56$ (95\%CI: $-2.22,3.35), \mathrm{t}=$ $0.38, \mathrm{p}=.71$; two-month: difference $=1.28(95 \% \mathrm{CI}$ : $-0.72,3.28,), \mathrm{t}=1.25, \mathrm{p}=.21$; four-month: difference $=$ -0.73 (95\%CI: $-2.55,1.09), \mathrm{t}=-0.86, \mathrm{p}=.39$; six-month: difference $=-1.04(95 \% \mathrm{CI}:-2.76,0.67) ; \mathrm{t}=-1.25, \mathrm{p}=$ $.21)$.

\section{Discussion}

GER frequency and symptoms, as measured by the IGERQ-R score, decreased significantly with age. The age pattern of the I-GERQ-R score and regurgitation frequency was different with a steady decline seen in the IGERQ-R scores while regurgitation frequency was fairly constant until six months of age. The effect of colicassociated symptoms may have undue influence on the I-GERQ-R score in the first two to four months of age.

A drop in the I-GERQ-R score of five or six is considered clinically important, while a three-point drop is considered minimally important[10]. We found a 
Table 1 Infant Gastroesophageal Reflux Questionnaire Revised (I-GERQ-R) scores by visit.

\begin{tabular}{lcccc}
\hline Visit & Mean & Standard Error & Median & Interquartile Range \\
\hline $\begin{array}{l}\text { One-month } \\
(n=94)\end{array}$ & 11.74 & 5.98 & 10 & 7 to 16 \\
$\begin{array}{l}\text { Two-month } \\
(n=96)\end{array}$ & 9.97 & 4.92 & 9 & 6 to 13 \\
$\begin{array}{l}\text { Four-month } \\
(n=100)\end{array}$ & 8.44 & 4.386 & 8 & 5 to 11 \\
$\begin{array}{l}\text { Six-month } \\
(n=105)\end{array}$ & 6.97 & 4.05 & 7 & 4 to 10 \\
\hline
\end{tabular}

clinically meaningful drop in the average from one month of age to six months of age and a minimally important drop from one month of age to four months of age and from two months of age to six months of age. However, our population was unselected, so lower I-GERQ-R scores on average than those referred for evaluation of GER would be expected. Consequently, any changes in I-GERQ-R scores would be tempered by a floor effect, which is also suggested by the narrowing of the standard error with age.

Despite the high prevalence of GER in the first year of life, this condition has received limited study. In a 1997 study of 948 infants, peak regurgitation (at least one episode of regurgitation a day) occurred in $51 \%$ at $0-3$ months, in $67 \%$ of four-month-olds, and in $5.4 \%$ at 10 to 12 months[12].

One-year follow-up on infants who regurgitated daily at 6 to 12 months of age found that none were still regurgitating, but these infants were more likely to report feeding refusal, taking more than one hour to eat a meal, and parents dreading mealtimes[13]. In our population at least one episode of regurgitation was reported in the previous day in $82 \%, 77 \%, 83 \%$, and $67 \%$



of infants at the one-month, two-month, four-month, and six-month visits, respectively.

In Adelaide, Australia, a peak prevalence $(41 \%)$ of "spilling" more than half of their feedings occurred between 3 and 4 months of age. The prevalence decreased to less than $5 \%$ by 14 months of age[14]. In Italy, $7.1 \%$ of infants had two or more episodes of regurgitation per day for 3 or more weeks. All had improved at 3-month follow-up[15]. In another Italian study of 2879 infants in the first six months of life, $23.1 \%$ had regurgitation and $20.5 \%$ had colic[16].

Several studies have focused on irritable infants. Jordan et al. found that $22.8 \%$ of irritable infants had a reflux index (RI) (percentage of total time the esophageal $\mathrm{pH}$ is less than 4$) \geq 10 \%[17]$. Heine et al. reported that $4.2 \%$ of irritable infants under 3 months of age had a RI $\geq 10 \%$ while $21.7 \%$ of infants three months and older did[18].

Crying duration in infants peaks at six weeks of age with the major concentration between $5 \mathrm{pm}$ and $11 \mathrm{pm}$ with an average of 2.75 hours per day[6,7]. Colic, often defined as three or more hours of crying per day for three or more days per week for longer than two to three weeks, peaks at the same age[19] and has an incidence that ranges from $16 \%$ to $20.5 \%[16,19,20]$.

Recommended treatment for GER generally consists of parental education, reassurance, and anticipatory guidance[21]. Whether or not an infant is "excessively" irritable or has "troublesome" symptoms is a highly subjective assessment. There is no evidence to indicate that irritability in the absence of regurgitation in infants is related to esophagitis or GER symptoms[18]. The benefit of acid suppression in infants with GER who have either perceived dysphagia or irritability has not been established[3,22].

All infants have some GER,[23] the question is which infants, if any, warrant evaluation and treatment. A recent consensus paper concluded that for infants there is no symptom or symptom complex that is diagnostic of GERD or predicts the response to therapy and there is no consistent correlation between symptoms and an elevated RI or histiological evidence of esophagitis[3]. Environmental smoke exposure has had mixed results with one study finding no association,[14] and two studies finding a positive association $[24,25]$. Our study found no association between GER symptoms and smoking or breastfeeding. A positive association has been shown between GERD and private insurance,[14] infants with lower birthweights, shorter gestation,[16] and possibly a cow's milk protein allergy $[8,17,26]$. The most consistent symptom associated with GERD was frequent regurgitation[18,27]. Regurgitating greater than five time per day had a specificity of $70.9 \%$, but a positive predictive value of $22.2 \%$ [27]. 
Table 2 Results of individual questions of the Infant Gastroesophageal Reflux Questionnaire Revised (I-GERQ-R) by age.

\begin{tabular}{lcccc}
\hline Question & One-month & Two-month & Four-month & Six-month \\
\hline Regurgitation frequency* & $1.12(0.09)$ & $1.19(0.09)$ & $1.24(0.09)$ & $0.93(0.08)$ \\
Regurgitation volume & $1.35(0.07)$ & $1.24(0.07)$ & $1.34(0.07)$ & $1.08(0.08)$ \\
Regurgitation discomfort & $1.05(0.11)$ & $0.90(0.10)$ & $0.72(0.09)$ & $0.54(0.08)$ \\
Refuse feed when hungry & $0.24(0.05)$ & $0.21(0.05)$ & $0.28(0.07)$ & $0.24(0.05)$ \\
Stop feed when hungry & $0.66(0.08)$ & $0.52(0.08)$ & $0.50(0.07)$ & $0.45(0.07)$ \\
Cry during/after feed & $1.27(0.12)$ & $0.90(0.10)$ & $0.57(0.07)$ & $0.45(0.06)$ \\
Cry greater than usual & $1.21(0.11)$ & $0.90(0.09)$ & $0.87(0.09)$ & $0.85(0.09)$ \\
Cry duration* & $0.93(0.09)$ & $0.77(0.08)$ & $0.60(0.07)$ & $0.55(0.06)$ \\
Hiccups & $2.68(0.08)$ & $2.33(0.10)$ & $1.57(0.10)$ & $1.25(0.08)$ \\
Arching & $1.13(0.10)$ & $0.86(0.10)$ & $0.72(0.08)$ & $0.57(0.08)$ \\
Apnea (awake/struggle) $\dagger$ & $0.12(0.05)$ & $0.14(0.05)$ & $0.0)$ & $0.02(0.02)$ \\
Turned bluet & $0(0)$ & $0.02(0.02)$ & $0.02)$ & $0(0)$ \\
Overall severity§ & $1.37(0.11)$ & $1.23(0.11)$ & $1.18(0.10)$ & $0.88(0.09)$ \\
\hline
\end{tabular}

Scores for each question ranged from 0 to 4 except where indicated.

* Score for question ranged from 0 to 3.

+ Score for question ranged from 0 to 2 .

$\S$ Question asked as part of I-GERQ-R, but score not incorporated into I-GERQ-R score.

Mean score (Standard deviation)

Adding to the difficulty of identifying and properly diagnosing infants with GERD, there is only poor to fair agreement between finding an RI $\geq 10 \%$ and a positive esophageal biopsy[18,28]. While esophagitis may be a significant determinant of long-term outcome,[29] the dangers of an $\mathrm{RI} \geq 10 \%$ in the absence of esophagitis are unknown.

With the predominance of colic symptoms in the first months of life and a decreased risk of GERD under three-months of age, GERD should not be considered a likely diagnosis until three months of age, and treatment should be reserved for those with histological changes in the lining of the esophagus.

This study was limited by our population: a rural community in which the medical center and a state university are the two biggest employers. Consequently, our population may be more highly educated than other rural populations in the northern Midwest. We had very few of our participants drop out and only a few mothers who refused to participate. We were also limited by lack of access to $\mathrm{pH}$ monitoring and pediatric esophogastroduodenoscopy.

Our study highlights the limitations of the I-GERQ-R, which is the only available validated tool to assess GER symptoms in infants. To date, its use has been limited $[10,30,31]$. Without a clear link between symptoms and disease, the clinical usefulness of the I-GERQ-R may be limited. Expanded experience with the I-GERQ-R is needed, especially at ages when colic-associated symptoms predominate. The values of the I-GERQ-R, or a subset of the items in the I-GERQ-R, that are predictive of GERD may vary with age, and this may need to be taken into consideration when using this tool.

\section{Conclusion}

GER symptoms, as measured by the I-GERQ-R, decrease over the first six-months of life in otherwise healthy infants. Scores in the first months of life may be dominated by colic-associated symptoms.

\section{About the Authors}

RSVH is a Clinical Professor in the Department of Pediatrics and Human Development at Michigan State University College of Human Medicine.

MRS is an Assistant Professor in the Department of Family Medicine at Michigan State University College of Human Medicine and an Assistant Director at the Marquette Family Medicine Residency Program.

\section{Abbreviations}

(I-GERQ-R): Infant Gastroesophageal Reflux Questionnaire Revised; (GER): gastroesophageal reflux; (GERD): gastroesophageal reflux disease; (LES): lower esophageal sphincter; (RI): reflux index; (SD): standard deviation; (SE): standard error.

\section{Acknowledgements}

We thank Susan Orenstein, MD and the staff at Children's Hospital of Pittsburgh and the University of Pittsburg for use of the Infant Gastroesophageal Reflux Questionnaire Revised. ${ }^{\circledR}$ 2004, University of Pittsburgh.

The Gerber Foundation provided a grant supporting the research but had no role in the design and conduct of the study; collection, management, analysis, and interpretation of the data; nor the preparation, review, or approval of the manuscript. 


\section{Author details}

'Department of Pediatrics and Human Development, Michigan State University College of Human Medicine, Marquette, Michigan, USA. ${ }^{2}$ Department of Family Medicine, Michigan State University College of Human Medicine, Marquette, Michigan, USA.

\section{Authors' contributions}

Both authors contributed to every aspect of the study, with the exception that the statistical analysis was performed by the first author (RSVH). All authors have read and approved the final manuscript.

\section{Competing interests}

The authors declare that they have no competing interests.

Received: 7 October 2009

Accepted: 11 February 2010 Published: 11 February 2010

\section{References}

1. Mittal RK, Holloway RH, Penagini R, et al: Transient lower esophageal sphincter relaxation. Gastroenterology 1995, 109:601-610.

2. Sherman PM, Hassell E, Fagundes-Neto U, et al: A global, evidence-based consensus on the definition of gastroesophageal reflux disease in the pediatric population. Am J Gastroenterol 2009, 104:1278-1295.

3. Vandenplas Y, Rudolph CD, Di Lorenzo C, et al: Pediatric gastroesophageal reflux clinical practice guidelines: joint recommendations of the North American Society for Pediatric Gastroenterology, Hepatology, and Nutrition (NASPGHAN) and the European Society for Gastroenterology, Hepatology, and Nutrition (ESPGHAN). J Pediatr Gastroenterol Nutr 2009, 49:498-547.

4. Khoshoo V, Edell D, Thompson A, Rubin M: Are we overprescribing antiflux medication for infants with regurgitation?. Pediatrics 2007, 120:946-949.

5. Barr RG: Colic and crying syndromes in infants. Pediatrics 1998, 102:1282-1286.

6. Brazelton TB: Crying in infancy. Pediatrics 1962, 29:579-588,

7. Wessel MA, Cobb JC, Jackson EB, Harris GS Jr, Detwiler AC: Paroxysmal fussing in infancy, sometimes called "colic". Pediatrics 1954, 14:421-435.

8. Hill DJ, Heine RG, Cameron DJS, Catto-Smith AG, Chow CW, Francis DEM, Hosking CS: Role of food protein intolerance in infants with persistent distress attributed to reflux esophagitis. J Pediatr 2000, 136:641-647.

9. Oberklaid F: Persistent crying in infancy: a persistent clinical conundrum. J Paediatr Child Health 2000, 36:297-298.

10. Kleinman $L$, Rothman $M$, Strauss $R$, et al: The infant gastroesophageal reflux questionnaire development and validation as an evaluative instrument. Clin Gastroenterol Hepatol 2006, 4:588-596.

11. Storms MR, Van Howe RS: Birthweight by gestational age and sex at a rural referral center. J Perinatol 2004, 24:236-240.

12. Nelson SP, Chen EH, Syniar GM, et al: Prevalence of symptoms of gastroesophageal reflux during infancy: a pediatric practice-based survey. Arch Pediatr Adolesc Med 1997, 151:569-572.

13. Nelson SP, Chen EH, Syniar GM, et al: One-year follow-up of symptoms of gastroesophageal reflux during infancy. Pediatrics 1998, 102:e67.

14. Martin AJ, Pratt N, Kennedy D, Ryan P, Ruffin RE, Miles H, Marley J: Natural history and familial relationships of infant spilling to 9 years of age. Pediatrics 2002, 109:1061-1067.

15. Miele E, Simeone D, Marino A, Greco L, Auricchio R, Novek SJ, Staiano : Functional gastrointestinal disorders in children: an Italian prospective study. Pediatrics 2004, 114:73-78.

16. lacono G, Merolla R, D'Amico D, Bonci E, Cavataio F, Di Prima L, Scalici C, Indinnimeo L, Averna MR, Carroccio A, the Paediatric Study Group on Gastrointestinal Symptoms in Infancy: Gastrointestinal symptoms in infancy: a population-based prospective study. Digest Liver Dis 2005, 37:432-438.

17. Jordan B, Heine RG, Meehan M, Catto-Smith AG, Lubitz L: Effect of antireflux medication, placebo and infant mental health intervention on persistent crying: a randomized clinical trial. J Paediatr Child Health 2006, 42:49-58.

18. Heine RG, Jaquiery A, Lubitz L, Cameron DJS, Catto-Smith AG: Role of gastro-oesophageal reflux in infant irritability. Arch Dis Child 1995, 73:121-125.
19. Hide DW, Guyer BM: Prevalence of infant colic. Arch Dis Child 1982, 57:559-560.

20. Crowcroft NS, Strachan DP: The social origins of infantile colic: questionnaire study covering 76,747 infants. Br Med J 1997, 314:1325-1328.

21. Rudolph CD, Mazur LJ, Liptak GS, et al: Guidelines for evaluation and treatment of gastroesophageal reflux in infants and children: recommendations of the North American Society for Pediatric Gastroenterology, Hepatology, and Nutrition. J Pediatr Gastroenterol Nutr 2001, 32(Suppl2):S1-S31.

22. Rudolph CD: Are proton pump inhibitors indicated for the treatment of gastroesophageal reflux in infants and children?. J Pediatr Gastroenterol Nutr 2003, 37(Suppl):S60-S64.

23. Vandenplas Y, Goyvaerts H, Helvin R, et al: Gastroesophageal reflux as measured by 24-hour $\mathrm{pH}$ monitoring in 509 infants screened for risk of sudden infant death syndrome. Pediatrics 1991, 88:834-840.

24. Shabib SM, Cutz E, Sherman PM: Passive smoking is a risk factor for esophagitis in children. J Pediatr 1995, 127:435-437.

25. Alaswad B, Toubas PL, Grunow JE: Environmental tobacco smoke exposure and gastroesophageal reflux in infants with apparent lifethreatening events. J Okla State Med Assoc 1996, 89:233-237.

26. lacono G, Carroccio A, Cavataio F, Montalto G, Kazmierska I, Lorello D, Soresi M, Notarbartolo A: Gastroesophageal reflux and cow's milk allergy in infants: a prospective study. J Allergy Clin Immunol 1996, 97:822-827.

27. Heine RG, Jordan B, Lubitz L, Meehan M, Catto-Smith AG: Clinical predictors of pathologic gastro-oesophageal reflux in infants with persistent distress. J Paediatr Child Health 2006, 42:134-139.

28. Moore DJ, Tao BS, Lines DR, Hirte C, Heddle ML, Davidson GP: Doubleblind placebo-controlled trial of omeprazole in irritable infants with gastroesophageal reflux. J Pediatr 2003, 143:219-223.

29. Shephard RW, Wren J, Evans S, Lander M, Ong TH: Gastroesophageal reflux in children. Clinical profile, course and outcome with active therapy in 126 cases. Clin Pediatr (Phila) 1987, 26:55-60.

30. Orenstein SR, McGowan JD: Efficacy of conservative therapy as taught in the primary care setting for symptoms suggesting infant gastroesophageal reflux. J Pediatr 2008, 152:310-314.

31. Khoshoo V, Dhume P: Clinical response to 2 dosing regimens of lansoprazole in infants with gastroesophageal reflux. J Pediatr Gastroenterol Nutr 2008, 46:352-354.

\section{Pre-publication history}

The pre-publication history for this paper can be accessed here:http://www. biomedcentral.com/1471-2431/10/7/prepub

doi:10.1186/1471-2431-10-7

Cite this article as: Van Howe and Storms: Gastroesophageal reflux symptoms in infants in a rural population: longitudinal data over the first six months. BMC Pediatrics 2010 10:7.

\section{Submit your next manuscript to BioMed Central and take full advantage of:}

- Convenient online submission

- Thorough peer review

- No space constraints or color figure charges

- Immediate publication on acceptance

- Inclusion in PubMed, CAS, Scopus and Google Scholar

- Research which is freely available for redistribution 